CUPAUAM. 17-1990, 143-167

\title{
EN TORNO A LA TIPOLOGIA DE LUCERNAS ROMANAS: PROBLEMAS DE NOMENCLATURA
}

\author{
ANGEL MORILLO CERDAN \\ DePto. PREH. y ARQUeOLogIA \\ UNIVERSIDAD AUTONOMA DE MADRID.
}

\section{Resumen}

La multiplicación tipológica y la ausencia de un criterio definido de clasificación de lucernas cerámicas, suelen provocar numerosos problemas de identificación formal. Cada vez resulta más imprescindible una armonización terminológica a partir de estudios ya existentes. Presentamos aquí un cuadro comparativo de las tipologías más conocidas y algunas propuestas que faciliten la futura catalogación de piezas.

\section{Summary}

The multiplication of typologies and the lack of definite criteria to classify ceramic lamps causes many problems of typological identification. It is now imperative to reach a terminological unification, based in previous research. We present a comparative table of the most important typologies and suggest some guidelines for future cataloguing of lamps.

El conocimiento sobre lucernas romanas ha progresado de forma significativa en los últimos veinte años. La mayor parte de las Memorias de Excavación recogen este material. La publicación de catálogos de colecciones y museos más importantes se halla en una fase muy avanzada. Los análisis químicos de pastas así como los estudios iconográficos, de producción y comercialización abren nuevas vias de aproximación al tema con prometedores resultados. En cuanto a la elaboración tipológica, el avance ha tenido más transcendencia desde el punto de vista de la cantidad que de la calidad de los estudios. Disponemos de un elevado número de clasificaciones procedentes de diversos puntos del ámbito romano, pero se hace patente la carencia de un criterio unitario de sistematización tipológica. Tal hecho invalida buena parte de la documentación obtenida por los investigadores contemporáneos.

No existe un "Corpus" similar al de otras producciones cerámicas que pueda servir como guía. Ni siquiera contamos con catálogos regionales bien constatados arqueológicamente. 
Cualquier estudio sobre este tipo de material lleva al investigador a enfrentarse necesariamente con un cúmulo de clasificaciones morfológicas de origen, estructura y terminología muy variada. Es necesario llevar a cabo una labor previa de revisión de cada una de ellas, para despues cotejarlas buscando equivalencias y semejanzas con el conjunto de piezas seleccionado. Supone un trabajo largo, complicado y poco gratificante.

El principal problema reside en la multiplicación de tipos causada por la existencia de clasificaciones pocas veces coincidentes. Cada autor suele emplear su propia morfología. Crea denominaciones y apartados a su gusto, buscando sin duda la facilidad en el estudio de sus materiales. No es corriente la utilización de sistematizaciones ajenas. Sólo en los últimos años la inclusión de una pequeña relación de correspondencias respecto a los autores más conocidos se ha convertido en una práctica habitual. Muchas formas son coincidentes, pero el hecho de que aparezcan con nomenclatura distinta puede inducir a error. En otros casos la presencia o ausencia de decoración provoca la indecisión respecto al grupo al que pertenecen.

La variedad tipológica en buena parte obedece a la existencia de diferentes criterios de clasificación, selecionados por los investigadores según su confianza en los mismos. El criterio morfológico es el más utilizado. Hemos de tener en cuenta que la mayoría de las lucernas conservadas en museos y colecciones públicas y privadas ha sido reunidas con un criterio coleccionista y por lo tanto carecen de indicación estratigráfica. La forma se destaca como la característica más visible. Los catálogos anteriores a 1970 suelen basarse exclusivamente en este aspecto (Dressel, 1889; Walters, 1914; De Brun y Cagniere, 1937; Lerat, 1954 entre otros). Incluso algunos autores posteriores siguen considerandolo como el más util (Provoost, 1976; Bailey, 1980; Amare, 1988).

Las similitudes formales configuran un prototipo. Datos fundamentales a tener en cuenta son la longitud y anchura de la lámpara, el diámetro y la decoración del disco, la configuración del depósito, piquera y asa, la anchura del margo y el número y disposición de las molduras interiores, así como el perfil y anchura de las paredes de la lucerna. Normalmente los grupos generales se establecen a partir de los caracteres más determinantes, mientras las subdivisiones atienden a los detalles en orden de importancia decreciente. Cada autor considera prioritario alguno de estos rasgos morfológicos, aunque a veces se equivoque. La estructura y dimensión del cuerpo constituye el dominante para la mayoría, mientras que otros catálogos parecen estructurar su tipología en torno a los cambios en la configuración del pico (Dressel, 1889). Con frecuencia cometen el error de multiplicar el número de divisiones y subdivisiones o, por el contrario, simplifican excesivamente.

El segundo criterio a tener en cuenta es el cronológico. Contamos con muy pocas publicaciones que recojan datos estratigráficos concretos proporcionados por las lucernas y los materiales arqueológicos asociados. Lo más común en este tipo de clasificaciones suele ser la datación aproximada mediante indicaciones generales: las piezas con líneas elegantes y estilizadas, decoradas con escenas de raiz helenística y profundo relieve se consideran anteriores a las toscas y gruesas con motivos decorativos muy sumarios. Esta tendencia, registrada en todas las manifestaciones plásticas romanas, ha sustituido frecuentemente a la constatación arqueológica real de las lucernas de cada periodo. Por otro lado, la utilidad de las marcas de alfarero como criterio cronológico se halla en entredicho. El descubrimiento de una tupida red comercial centrada en las imitaciones y el intercambio de moldes entre oficinas productoras prolonga la duración temporal de las mismas durante varias décadas.

Por regla general toda tipología suele combinar en mayor o menor medida ambos métodos, el morfológico y el cronológico. A partir de la publicación del primer trabajo con dataciones 
arqueológicas (Loeschcke, 1919) se ha desarrollado una evidente interrelación mutua: por una parte la influencia jerarquizadora de las tipologías formales sobre las secuencias estratigráficas; por otro, los datos cronológicos que éstas últimas aportan a aquellas. El resultado ha sido una síntesis bastante acabada pero sólo hasta cierto punto aceptable, muy compleja, de dificil aplicación práctica y problemática adaptación a regiones distintas.

Mención aparte merece la naturaleza de origen de los catálogos de lucernas romanas. Centroeuropa es sin duda el área mejor conocida, cuyas cronologías,tomadas directamente de observaciones arqueológicas, se ajustan mejor a la realidad. Los resultados en la Cuenca mediterránea son menos satisfactorios. Los estudios suelen ser parciales, con métodos estrictamente tipológicos y dataciones adaptadas. Los grandes centros de producción italianos permanecen inéditos, al igual que la mayor parte de los materiales franceses y portugueses. Tan sólo el Norte de Africa y algunas ciudades orientales (Corinto, Tarso, Olimpia, Atenas) muestran un nivel aceptable de conocimiento. Por lo que serefiere a Gran Bretaña, la esmerada publicación del Museo Británico no aclara la composición de los materiales insulares.

El caso español resulta similar al de otros paises de nuestro entorno, con la diferencia que el volumen de material publicado es aún menor y sólo en contadas ocasiones procede de excavaciones realizadas con una metodología científica. No se han elaborado tipologías sustentadas por el suficiente número de piezas como para tenerlas en consideración. Contamos con algunos intentos dignos de reconocimiento, pero se refieren a ciudades o zonas muy concretas (PALOL, 1948-9 para Ampurias; Fernández Chicarro, 1952 para Sevilla; Amare, 1988, para el Valle del Ebro). En algunas ocasiones la carencia de una metodología aceptable invalida el trabajo (Alvarez Ossorio, 1942).

En definitiva la cuestión que queda planteada es si el prototipo o modelo actual de evolución de lucernas responde a una realidad histórica con una cronología concreta o no pasa de ser una hipótesis de trabajo elaborada a partir de formas mediterráneas y cronología de áreas periféricas.

\section{PRINCIPALES TIPOLOGIAS}

Las principales clasificaciones tipológicas aparecen recogidas en varias síntesis. La relación más completa es la de Ponsich (Ponsich, 1961). No pretendo repetir aquí con detalle lo ya expuesto en otro lugar, sino unicamente realizar una breve reseña de los aspectos más significativos. El criterio de selección de tipologías para este trabajo se ha fundamentado más que en su calidad en su transcendencia desde el punto de vista de la investigación posterior. De ahí que haya descartado previamente algunos estudios a pesar de su incuestionable aportación (entre otros Fink, 1901, Waldhauuer, 1914, Haken, 1958). Varios más lo fueron trás su análisis.

\section{H.Dressel (1899)}

Su trabajo, publicado en 1899 en el C.I.L., constituye la primera clasificación formal de lucernas realizada mediante una metodología científica. Abarca treinta y un tipos. Resulta muy completo, pero su excesiva diversificación y la sutil diferencia entre algunos tipos como el grupo 14-16 complica su utilización. El hecho de ser una de las pocas clasificaciones basadas en materiales italianos supone una ventaja adicional, apenas valorada. La principal objeción a este catálogo es que aunque presenta un ordenamiento cronológico (sólo errado respecto a las lucernas de canal) no se precisa la datación de cada una de las formas. 


\section{H.B. Walter (1914)}

Primera de las clasificaciones de la colección del Museo Británico, una de las mejores del mundo, pero concentrada sólo en algunas formas determinadas. Multiplica excesivamente los tipos, más aún que Dressel. Resalta las peculiaridades de cada pieza, pero no hace hincapié en las características comunes del conjunto. Por otro lado sus dibujos no coinciden exactamente con las fotografías de las piezas. Es el primer investigador en asignar cronologías generales a los grandes grupos.

\section{S. Loeschcke (1919)}

A pesar de su fecha tan temprana resulta una de las tipologías más completas y organizadas, perfectamente válida hoy en dia. Sacrifica la variedad en aras de la claridad. Constituye el modelo para gran parte de los estudios posteriores (Broneer, Ivanyi entre otros). Aún así su principal aportación reside en el campo de la cronología, ya que es el primer trabajo basado en una estratigrafía arqueológica. Precisa la exacta duración temporal de las lucernas de volutas con piquera triangular, estableciendo varias subdivisiones de acuerdo con ésta, que han sido aceptadas por todos los autores posteriores. Asimismo sitúa cronológicamente el tipo Firmalampen. El yacimiento estudiado arranca de los primeros años del Imperio, motivo por el que carece de lucernas republicanas.

\section{O. Broneer (1930)}

Memoria de las excavaciones de Corinto, primera que estudia las lucernas romanas en un ámbito griego. Tipología bien organizada, pero sin tabla gráfica de formas, y quiza con demasiados subtipos. Indica correspondencias formales respecto a Loeschcke. Distingue correctamente entre formas oriundas, de tradición helenística y las importadas de Occidente como las de volutas y Firmalampen. Las lucernas republicanas son sustituidas por equivalentes helenísticas. Individualiza por primera vez como grupo independiente las lucernas de volutas con asa plástica y empieza a precisar los ejemplares de los siglos II-III. La cronología presenta algunas particularidades respecto a Loeschcke, quizá por motivos geográficos.

\section{F. Doumergue (1932)}

En realidad no puede considerarse una tipología, aunque algunos autores la citen como tal. Recoge los materiales del Museo de Orán separándolos en siete grandes grupos cronológicos o culturales. La brevedad de las descripciones y la imprecisión cronológica hacen este catálogo dificilmente aceptable. Su error más destacado consiste en situar las lucernas de piquera redondeada sin volutas en el siglo I d. C.

\section{Ivanyi (1935)}

Interesante catálogo que se basa en un fondo de más de 5000 lucernas halladas en Hungría, la Panonia romana. Explicaciones breves, concisas y bien constatadas tipologicamente. Loeschcke y Bronner constituyen los indiscutibles modelos de referencia. No incluye una tabla de for- 
mas, pero sí equivalencias respecto a los autores anteriores. El criterio para individualizar los grupos principales es la decoración y la firma. Precisa con escaso margen de error la cronología de los tipos principales de Firmalampen. Las dataciones parecen bastante rigurosas, aunque algunas no coinciden con Loeschcke, hecho que parece deberse a la situación periférica de Panonia, o tal vez a un error de interpretación.

\section{P. de Brun y S. Cagniere (1937)}

Inicia una serie de tipologías excesivamente simplificadas, que evitan detalles a su juicio innecesarios. Se estudia la colección del Museo Calvet de Avignon (Francia), que carece de lucernas republicanas. No existe soporte gráfico para la clasificación. La cronología resulta muy sumaria y está tomada de otros autores. En conjunto supone un retroceso respecto a trabajos anteriores.

\section{F. Alvarez-Ossorio (1942)}

Primera de las tipologías españolas, basada en un conjunto de piezas pertenecientes a los fondos del Museo Arqueológico Nacional y previamente seleccionadas. Su utilidad es practicamente nula. Tiene en consideración solamente algunos de los tipos existentes, organizándolos mediante un criterio muy heterogéneo. La terminología empleada resulta absolutamente arcaica y la ausencia de tabla de formas así como de buenas fotografías dificulta enormemente su asimilación a otros catálogos. En muchos casos no tenemos seguridad respecto al tipo al que hace referencia. La cronologia es unicamente orientativa y prestada de otros investigadores.

\section{P .de Palol (1948-9)}

La clasificación de los materiales empuritanos realizada por Palol sigue siendo hoy en dia la mejor de las españolas. Tipología muy completa y organizada, que recoge practicamente todas las variantes existentes en el Mediterráneo Occidental, aunque no incluye dibujos de las mismas. El modelo indiscutible es Loeschcke, de quien se citan las equivalencias formales, aunque Walters e Ivanyi también son tenidos en cuenta. Su aportación más interesante consiste en situar cronologicamente por primera vez las piezas de época republicana, que él considera augusteas. Identifica un nuevo tipo de lucerna de canal, coincidiendo con Walters.

\section{H. Goldman (1950)}

Esta investigadora se basa por completo en Broneer, tanto en fechas como en tipos, quiza por ser el único trabajo que estudia el Oriente mediterráneo. Indica la correspondencia respecto a las formas del susodicho autor. La atribución de bastantes piezas resulta demasiado aventurada, ya que se fundamenta exclusivamente en la morfología del margo. Por otro lado, su simplicidad y esquematismo facilita su comprensión. Entre los hallazgos de Tarso no se cuentan ni las lucernas republicanas ni Firmalampen, al igual que ocurría en Corinto. Repite la datación de Bronner, precisando unicamente las formas griegas de piquera redondeada y de la variedad acorazonada. 


\section{N. Lamboglia y A. Beltran (Dressel-Lamboglia) (1952)}

Lamboglia mantiene la clasificación de Dressel practicamente sin cambios, pero incorpora el valor cronologico de cada forma, del que este autor había prescindido al desconocer, entre otras cuestiones, la datación de la sigillata. Ordena las formas cronologicamente precisando muy bien la evolución tipológica a través del tiempo. Incorpora sólo un nuevo grupo al catálogo de Dressel: las lucernas de canal largo y cerrado. Las piezas republicanas se adelantan hasta el siglo II-I a. C., pero sin mayores precisiones.

\section{Fernández Chicarro (1952)}

Estudio de las lucernas del Museo de Sevilla, que establece tan solo cinco grandes grupos con un criterio exclusivamente cronológico. No utiliza el criterio tipológico y en consecuencia algunas peculiaridades no aparecen recogidas. No parece que fuera concebida como una auténtica tipología formal.

\section{Lerat (1954)}

Clasificación muy completa, diversificada y bien estructurada, si bien la proliferación de categorías y subgrupos con nomenclatura mixta de letras y números complica la lectura de las correspondencias y lleva a autores posteriores a algunos errores de cita. Recoge los materiales de una colección pública. Uno de sus aspectos más interesantes consite en la inclusión de las equivalencias morfológicas completas de cada una de las formas respecto a los trabajos de Loeschcke, Walters y Broneer. La carencia de cronología constituye la única objeción a este minucioso estudio, uno de los ejemplos más claros de tipología exclusivamente formal.

\section{Menzel (1954)}

Catálogo de las lucernas del Museo de Maguncia. Resulta muy completo pero poco sistematizado. El excesivo número de grupos y variantes complica su consulta. Sigue un criterio de organización cronológico, con fechas bastante ajustadas, a pesar de no ser de primera mano. En general no ha sido suficientemente valorado y tan solo algunos investigadores posteriores, en su mayoría centroeuropeos, lo tienen en consideración.

\section{Ponsich (1961)}

Trabajo bastante sistemático que incluye la práctica totalidad de las piezas de Marruecos. Ofrece un resumen de las tipologías anteriores y una comparación de las mismas en cuadros cronológicos y morfológicos. Esta innovación adquiere una importancia fundamental para los investigadores posteriores. A través de la combinación de los criterios cronológico y formal establece un corto número de grupos muy bien individualizados con una serie de variantes, que plasma en una tabla de figuras. Ponsich tiene en consideración las lucernas de varias excavaciones modernas que cuentan con estratigrafía, con lo que adquiere información temporal de primera mano. $\mathrm{Si}$ exceptuamos alguos rasgos menores, no existen grandes diferenciasentre el mateial norteafricano y el del resto del Occidente romano. Define el modelo de las tipologías más actuales. 


\section{J. Deneauve (1969)}

Deneauve estudia las lucernas de la región de Cartago, importante centro nervioso del mundo romano. Dentro de las publicaciones realizadas a lo largo de los últimos treinta años ésta, junto con la anterior, son prácticamente las más utilizadas y citadas por los autores posteriores. La razón de tal preferencia se halla, sin duda, en lacalidad de las mismas, realizadas mediante una metodología avanzada, que estudian grandes conjuntos de piezas de amplias regiones, muchas de ellas bien datadas arqueológicamente. Esto los hace adecuados para comparar con otros trabajos locales o regionales. La clasificación de este investigador es probablemente la mejor, la más completa, organizada y citada. Sigue el modelo de Ponsich en cuanto a la combinación de datos cronológicos y formales, pero perfecionado. La piquera sigue siendo uno de los elementos morfológicos determinantes. También puede observarse cierta influencia de los trabajos de Loeschcke y Lerat. Desarolla su propia tabla de formas con un número de éstas bastante adecuado, ni demasiado reducido, ni demasiado extenso, prescindiendo de muchos detales supérfluos que aparecen en otras clasificaciones. En cuanto a la cronología resulta algo más complicada que la de Ponsich, pero realiza algunas precisiones basadas en información directa. La posición de Cartago y su importancia comercial, sobre todo a partir del siglo III d. C., confieren a este trabajo una importancia excepcional para conocer mejor la producción de lucernas.

\section{Th. Szentleleky (1969)}

Publicado el mismo año que el de Deneauve sin duda constituye un intento con menores pretensiones que el de este autor. A pesar de ello, resulta un buen catálogo elaborado a partir de un elevado fondo de lucernas húngaras. Abandona la organización a base de grupos y subgrupos, y se decanta por otra ordinal, muy sencilla, que facilita enormemente su consulta. Los grupos se establecen por la forma o el área geográfica de procedencia. Las indicaciones cronológicas son muy aproximadas, pero de nuevo se nos plantea el problema de si las peculiaridade en este campo se deben a una lectura erronea de los datos por parte del autor o a un característica regional. Especialmente llamativo resulta el caso de las lucernas delfiniformes, consideradas como republicanas por la mayoría de los autores, y que el autor sitúa entre el 25-75 d. C.

\section{G. Heres (1972)}

Incluye un número bastante elevado de piezas pertenecientes al Museo de Berlín. Tipología bastante completa y bien organizada, con cinco grupos morfológico-cronológicos y subvariantes, aunque no incluye la tabla de prototipos formales. Ofrece correspondencias respecto a Loeschcke, Broneer, Ivanyi y ocasionalmente alguna mención a otros autores. La cronología está muy bien establecida sobre todo en lo que se refiere a las lucernas de los siglos II-III d. C., todavía bastante desconocidas en este momento. LLama la atención la ausencia de Firmalampen en el conjunto, teniendo en cuenta su adscripción cronológica.

\section{Ricci (1974)}

En realidad no es una tipología, sino una revisión de las lucernas de época republicana y protoaugustea. Introduce algunas variantes desconocidas en la clasificación de Dressel y precisa de 
forma incontestable la cronología de cada una de ellas a partir de las estratigrafías arqueológicas. Ricci deja perfectamente establecido el marco temporal de las piezas republicanas. Otro mérito que hay que reconocer a esta autora es haber mantenido la terminología de Dressel.

\section{A. M. Alarçao y S. de Ponte (1976)}

La tipología resulta bastante clara, aunque el reducido número de piezas no permite una clasificación exhaustiva. Muy pocas lucernas se encuentran completas y faltan bastantes tipos. Se emplea un criterio mixto cronológico-morfológico. Incluye un cuadro de correspondencias tipológicas entre los materiales de Conimbriga y los trabajos de Deneauve, Dressel-Lamboglia, Ponsich, Ivanyi, Loeschcke y Palol, en el que se cometen algunos errores de identificación, tal vez sólo erratas tipográficas (por poner un ejemplo su B-II, 1 no corresponde al Deneauve, IVB, sino al IVD; igual podemos decir del B-I, 2b, que equivale al Dressel 14, no al Dressel 15). A cambio ofrece una cronología estratigráfica perfectamente contrastada, aunque no para todos los tipos.

\section{A. Provoost (1976)}

Primer intento de tipología general de lucernas romanas, muy exhaustiva pero complicada, con numerosas variantes y subgrupos. Define por primera vez los criterios de agrupación morfológica, que deben ser en primer término las características del depósito y sólo en casos concretos el asa o el pico. En general la secuencia evolutiva se encuentra bastante bien determinada. Provoost es quizá el autor que más atención presta a las lámparas bajoimperiales, muy descuidadas por la investigación. No aporta cronología de fuentes directas. Quizá la crítica más severa se centra en las escasas referencias a otros autores, especialmente latinos.

\section{A. Leibunndgut (1977)}

Trabajo rigurosamente científico, con una metodología muy actual, en el que se analizan las lucernas del territorio suizo. La tabla de formas es muy completa, quizá con excesivos apartados. Ofrece la correspondencia de todos los tipos con Loeschcke. Ejemplares datados, con fechas estratigráficas para cada pieza. Como suele ser corriente en las tipologías centroeuropeas, la cronología adquiere mayor significación que la forma.

\section{A. M. Bisi Ingrassia (1977)}

Tipología cuidada y bien organizada, basada en un elevado número de piezas aparecidas en las modernas excavaciones de Herculano. Consta de 11 formas con numerosas subvariantes, de las cuales 3 son de tradición helenística, 1 de transición, y 7 plenamente imperiales. La propia autora reconoce su inspiración en las clasificaciones de Loeschcke y Deneauve. La tabla de formas resulta muy similar a la de este último. Su principal aportación es cronológica. Precisa con escaso margen de error el periodo de uso de cada tipo. La existencia de una indiscutible fecha "ante querı" para el abandono del yacimiento (el año $79 \mathrm{~d}$. C.) ha permitido comprobar con seguridad que la mayoría de las variantes de lucernas de disco ya existen en una fecha tan temprana. 


\section{M. Bailey (1980)}

Bailey realiza un nuevo catálogo del Museo Británico bastante empleado en la actualidad, más que por su calidad por el volumen de piezas con que trabaja y las posibilidades de difusión del mismo. Estudio muy minucioso y sistemático, que incluye todas las formas ya establecidas y un enorme repertorio de escenas decorativas, así como correspondencias respecto a varias tipologías anteriores. La clasificación propiamente dicha resulta completísima, pero presenta algunas dificultades como utilizar letras del abecedario y no numerales para la nomenclatura de los excesivos tipos. Por otro lado, el criterio formal para la individualización de variantes resulta a veces forzado: por una ligerísima variación en el diámetro de una moldura o la especial conformación de una voluta se establecen notables diferencias cronológicas o de procedencia, lo que a todas luces resulta aventurado. Las lucernas republicanas están peor estudiadas, sin duda por constituir un volumen de material mucho menor.

\section{Pavolini (1981)}

No está planteada como una tipología al uso. Recoge la producción de lucernas itálicas entre el siglo III a. C. y el II d. C. Su estudio de las lucernas republicanas resulta inmejorable, tanto en el planteamiento como en la reseña bibliográfica. Establece varios tipos a partir de la forma y el área de producción, abandonando el concepto de una evolución lineal. La cronología y los mapas de difusión constituyen otros aciertos del autor.

\section{Ma. T. Amare (1988)}

La tipología de Amare, que sigue en gran medida el modelo de Provoost, constituye la tipología más reciente y completa entre las españolas. Ha sido elaborada con un criterio exclusivamente morfológico plasmado en una jerarquía estricta. Entre sus ventajas se cuenta la inclusión de todos los tipos existentes aunque no se documenten en el lote estudiado y la rigurosa aparición de correspondencias respecto a otros autores, si bien en las formas problemáticas resultan mínimas. El inconveniente más destacable es la imprecisión cronológica. Los materiales en su mayoría están descontextualizados, sin aval arqueológico, de tal manera que la datación se toma de otros autores sin aportar nada nuevo. Asimismo se echa en falta un catálogo de todos los materiales aragoneses que ha estudiado. La tabla de formas, al no tener en consideración cuestiones temporales, resulta la más completa y organizada de las realizadas.

\section{ESTUDIO COMPARATIVO}

Como se ha mencionado más arriba la catalogación de cualquier lote de piezas obliga a tomar contacto con este conjunto de clasificaciones y escoger el autor más adecuado. En vista de esta compleja situación creo necesaria la elaboración de un cuadro comparativo de formas y cronología entre las distintas tipologías.

Dentro de este trabajo se han tenido en cuenta algunas clasificaciones que dificilmente pueden pasar por tipologías y con bastante certeza en la mente de sus creadores no tenían este fin. Sin embargo los investigadores posteriores las citan como tales y de ahí que se hayan recogido, aunque no sean utilizadas. Tal es el caso de las de Doumergue, De Brun-Cagniere, Alvarez-Osso- 
rio y Fernández Chicarro. El estudio de Menzel ha sido eliminado en razón de su complejidad. Las clasificaciones de Pavolini y Bisi Ingrassia, de innegable calidad, no han sido tampoco incluidas. Esta, apenas citada por los investigadores posteriores, resulta demasiado local y está comprendida entre límites temporales muy próximos; Pavolini parece excesivamente detallista para nuestro objetivo. Por el contrario, y a pesar que no hace referencia más que a materiales republicanos, he decidido mantener el de Ricci por su determinante aportación cronológica.

Prescindo de las lucernas griegas y helenísticas, a excepción de las que ocupan el periodo de transición hacia las producciones tipicamente romanas, que reciben el término genérico de "republicanas". Asimismo las lucernas conocidas como "paleocristianas" están ausentes de este estudio, debido a que presentan una problemática especial, bastante bien definida. Por lo tanto nuestro estudio se concentra en un marco cronológico que se extiende entre el siglo I a. C. y los comienzos del IV d. C., aunque sólo se recogen las formas más conocidas y constatadas a lo largo del Imperio. Los tipos peculiares o variedades locales (egipcias, sirias y norteafricanas entre otras) tampoco se tienen en consideración. Las razones de esta selección previa hay que buscarlas en la necesidad de un esquema claro y aplicable de forma general.

La nomenclatura empleada vendrá encabezada por el enunciado más conocido del mismo tipo. Normalmente utilizaremos la tipología de Dressel, salvo en aquellas piezas no recogidas por este autor. A continuación se recogen todas las denominaciones que ha recibido cada una de las formas, pero sólo si coinciden exactamente de uno a otro autor. $\mathrm{Si}$, aunque sólo sea por la presencia de asa y decoración no coincidieran, no se reseña el tipo equivalente. No deseamos originar una nueva tipología y de ahí que hayamos renunciado a una ordenación propia. Al final de este trabajo se incluyen los cuadros comparativos dispuestos cronologicamente, aunque resulta de todos conocido que no existe una rígida evolución diacrónica. Ante el volumen de datos pido disculpas anticipadamente por cualquier posible error que haya podido cometer durante la búsqueda de correspondencias formales, o en su transcripción a estas páginas.

\section{LUCERNAS REPUBLICANAS}

\section{Tipo Dressel 2}

(Walters, 49-51; Palol, 1; Dessel-Lamb., 2; Lerat, IIC; Ponsich, IB; Deneauve I; Szentleleky b-1; Alarçao-Ponte, AI; Provoost, III-1, 3; Amare I-2, Ba)

Lucerna del tipo delfiniforme, de inspiración helenística. Cuerpo de sección bitroncocónica con disco cerrado y orificio central, piquera en yunque y asa posterior. En ocasiones puede presentar una aleta lateral. La denominación "Warzenlampen" se le ha dado en atención a la orla decorada con globulos o perlitas en filas concéntricas.

Esta forma ya aparece configurada en la publicación de Dressel, reapareciendo en otros conjuntos con material antiguo, republicano o de los primeros años de Augusto. La cronología del tipo ha estado sin embargo sujeta a fluctuaciones. Para algunos autores presenta una amplia duración temporal. Dressel-Lamboglia asigna los siglos II-I a. C.; Provoost entre el 275 y el I a. C; Palol rebaja su cronología hasta época augustea; Ricci la ha establecido a la largo del siglo I a. C., al igual que Walters, Ponsich y Deneauve. Mención especial merecen los materiales húngaros, que Szentleleky sitúa entre el 25-75 d. C., lo que parece ser un error más que una perduración. 


\section{Tipo Dressel 3}

(Walters, 73-74; Palol 2a; Dressel-Lamb., 3; Lerat III-1; Ponsich IC; Deneauve III; AlarçaoPonte A-2; Provoost IV-1, 2a, 1a; Leibungut II)

Tipo bastante similar al anterior con cuerpo circular, orla estrecha surcada por una nervadura, piquera en yunque y amplio disco plano y decorado. Asa posterior y dos aletas laterales simétricas. Prácticamente se documenta en conjuntos de la misma cronología que Dressel 2 y se le ha atribuido la misma cronología. Ricci lo encuentra documentado entre el 90 a. C. y el cambio de era. Leibundgut restringue su duración temporal en Suiza al 50-10 a. C. Sólo Provoost considera que aparece en los primeros años del siglo I d. C.

\section{Tipo Dressel 4}

(Palol, 3; Dressel-Lamb., 4; Lerat, III-1; Ponsich, IC; Deneauve, II; Szentleleky b-2; Provoost, IV-1, 2a 2a; Leibundgut, I; Amare III-1).

Lucerna del mismo tipo que los dos grupos anteriores con cuerpo muy alargado, orla estrecha decorada con molduras de disposición variada, asa anular acanalada y piquera en yunque, con el canal flanqueado por dos cabezas de ave (cisne o ibis). Esta peculiar decoración determina que se les de el nombre de "lucernas de cabeza de pájaro" o "Vogelkopflampen".

Este tipo de piezas resulta más abundante que otras de época republicana, aunque en el Mediterráneo Oriental siguen siendo muy raras. El tipo está perfectamente individualizado desde Dressel. Provoost se resiste a darles el nombre de Vogelkopflampen porque está decoración no aparece en todas las lucernas de este tipo, y las coloca como una variante de las delfiniformes (Provoost, 1976, 552, nota 31 ; Provoost, 564, nota 44). La mayoría de los autores está de acuerdo en que la cronología es más reciente y la producción se extiende a lo largo del principado de Augusto. Ricci ha establecido con claridad los límites temporales entre el 20 a. C. y el 10 d. C., información confirmada por Leibundgut en sus materiales.

\section{LUCERNAS DE VOLUTAS}

\section{Tipo Dressel 9 (9A, 9B, 9C)}

(Walters, 78-80; Loeschcke, IA, IB, IC; Broneer, XXII; Ivanyi, I; Dressel-Lamb., 9A, 9B, 9C; Palol, 6A, 6B, 6C; Goldman, XII; Lerat, III-2, A; Ponsich, II, A-1; Deneauve, IVA; Szentleleky, b-4; Heres, B; Alarçao-Ponte, BI, 1a; Provoost, IV-2, 10,1aa, IV-2, 1o, $2^{\mathrm{a}}, \mathrm{IV}-2,1^{\circ}, 3^{\mathrm{a}}$; Leibundgut, V, VI VII; Bailey, IA; Amare, IV-2, Aa, IV-2, Ab, IV-2, Ac)

Se caracterizan por tener la piquera triangular flanqueada por dos volutas, disco circular horizontal o concavo con escenas decorativas, margo estrecho y plano, y ausencia de asa. Los modelos para las lucernas de volutas hay que buscarlos en los ejemplares metálicos, que estaban perforados a los lados del pico para sujetarlos en el vacio mediante dos cadenillas. Constituyen uno de los conjuntos más numerosos, de gran cálidad técnica y artística y muy conocidos. Conforman la primera producción romana a gran escala, que llega a todos los rincones del Imperio. Posiblemente son una creación original de los talleres del Asia Menor (Balil, 1982, 247), adoptada rapidamente por los italicos. Por primera vez aparece en el ámbito griego un considerable 
volumen de lucernas idénticas a las occidentales, como atestiguan las publicaciones de Broneer y Goldman entre otros.

En razón de la variable longitud del pico triangular y el ángulo que éste forma con el depósito, Loeschke estableció tres subvariantes (Loeschke, 1919, 24-5)

A) Las volutas son más salientes que los vértices del pico y se unen con éstos por medio de líneas tangentes que convergen delante del mismo.

B) La anchura de los bordes y volutas es la misma y ámbos elementos se unen por líneas casi paralelas.

C) Los vértices del pico resultan más anchos que las volutas y se unen con ellas por medio de líneas divergentes

Poco tiempo después Loeschcke coteja esta clarificación con otros yacimientos y le asigna un valor cronológico, que aún hoy se mantiene. Las del primer tipo corresponden a la época de Augusto-Tiberio; el tipo B a la de Tiberio-Claudio; el tipo $\mathrm{C}$ se desarrollan durante el reinado de Neron y comienzos de la dinastia Flavia. La mayoría de los investigadores posteriores están de acuerdo en que pueden distinguirse tres grupos al menos desde el punto de vista cronológico, pero no todos consideran necesario individualizar cada uno de ellos dentro de las lucernas de piquera triangular. Tan sólo Palol, Leibundgut, Provoost y Amare han creado subdivisiones a tal efecto. Algunos catálogos atribuyen una fecha unitaria a todo el conjunto: Broneer le asigna todo el siglo I d. C, lo que sigue Goldman; Ponsich, Deneauve y Bailey mantienen la datación de Loeschcke pero sin separar las piezas en grupos. Ivanyi ha prolongado la cronología hasta tiempos de Marco Aurelio, lo que puede obedecer a una peculiaridad regional o de nuevo a una mala lectura de la información arqueológica. Por el contrario Heres confirma la datación de Loeschcke.

Dressel es el único investigador que distingue un tipo independiente de lucerna de volutas con piquera triangular con asa y volutas degeneradas (Dressel 10), que Lamboglia sitúa entre Tiberio y Claudio. Parece una variante local, sin difusión.

\section{Tipo Dressel 11}

(Walters, 81; Loeschcke, IV; Broneer, XXIII; Ivanyi, II; Dressel-Lamb., 11; Palol, 8; Goldman, XIII; Lerat, III-2, B-2; Ponsich, II, B-1; Deneauve, VA; Szentleleky, b-7; Heres C; Alarçao-Ponte, B-I, 2a; Provoost, IV-2, 2a , 1a; Leibudgut, XII; Bailey IB; Amare, IV-2, Ba)

Lucerna de volutas con piquera redondeada u ojival, sin asa. Las volutas apenas sobresalen del cuerpo. el resto de las características son muy parecidas al tipo anterior. Presenta una gran difusión en el mundo romano.

El tipo ya fue perfectamente definido por Dressel, y está recogido por todos los investigadores. Walters fue el primero en situarlo cronologicamente en la primera mitad del siglo I d. C. La fecha de inicio se ha mantenido a grandes rasgos, pero algunos autores posteriores han prolongado su producción hasta finales del siglo I d. C (Ponsich, Deneauve, Heres), e incluso principios del II (Ivanyi, Szenleleky, Provoost, Bailey). Da la impresión que al Norte de los Alpes, esta forma perdura durante más tiempo. Tan sólo Loeschcke le daba una datación tardo augustea.

Palol comete un error al identificar el tipo Loeschcke IV con su tipo 9, cuando en realidad corresponde a su 8 . Puede deberse a una errata involuntaria. 


\section{Tipo Dressel 12-13}

(Walters, 86-89; Loeschcke, III; Broneer, XXI-2; Ivanyi, III; Dressel-Lamb., 12-13; Palol, 7; Goldman, XI; Lerat, III-2, B-1; Ponsich, II, B-1; Deneauve, VB; Szentleleky, b-3; Heres, Aa, Ab y Ac; Alarçao-Ponte, B-I, 2c; Leibundgut, X y XI; Bailey, ID; Amare, IV-2, Bai)

Mientras la mayoría de los autores considera las lucernas de volutas de gran tamaño con piquera redondeada y gran asa plástica como un tipo único, tan sólo Dressel, Heres y Leibundgut distinguen dos grupos en atención al número de picos. Resulta una forma bastante individualizada y bien conocida en todas las regiones del Imperio, variante de la Dressel 11. Tan sólo Provoost las considera conjuntamente con este último tipo.

La cronología presenta mayores problemas. Loeschcke, a partir de su aparición en Haltern, considera estas piezas como augusteas; Broneer y Goldman las sitúan en el cambio de era; Ivanyi y Palol precisan su datación entre Augusto y los comienzos del reinado de Vespasiano, con perduraciones hasta Adriano entre los materiales húngaros. El criterio de estos investigadores es el que se acepta hoy día a grandes rasgos (Ponsich, Leibundgut). Para Alarçao su producción se concentra en un periodo más corto, aproximadamente en el segundo cuarto del siglo I d. C.

\section{Tipo Dressel 14-16}

Englobamos dentro de esta denominación tres tipos establecidos por Dressel: 14, 15 y 16. La razón es el parecido que existe entre los mismos. Parecen ser variantes locales de la misma forma, agrupadas en la mayoría de las clasificaciones posteriores. Existen sin embargo, ciertas diferencias cronológicas entre las mismas.

\section{Tipo Dressel 14}

(Walters, 83 y 85; Loeschcke, V; Broneer, XXIV; Ivanyi, VI; Dressel-Lamb., 14; Palol, 9; Goldman, XIV; Lerat, III-2, C; Ponsich, II, B-2; Deneauve, VD; Szentleleky, b-8; Heres, D; Alarçao-Ponte, B-I, 2b; Provoost, IV-3, 1a; Leibundgut, XIV-XV; Bailey, IC)

Características formales muy parecidas a los tipos anteriores. Asa posterior perforada, piquera redondead y margo más ancho delimitado en forma de volutas atrofiadas, cuyo extremo superior ha desaparecido, y el inferior termina en una especie de botón. Estas piezas suelen estar presentes en la mayoría de los conjuntos estudiados, pero en un volumen menor que otras de volutas.

La producción de las formas Dressel 9 y Dressel 11 es practicamente contemporánea, pero las lucernas con piquera redondeada sobreviven durante más tiempo abandonando las volutas dobles por semivolutas, y dando lugar a un nuevo tipo (Dressel 14-16). La transformación se verifica hacia mediados del siglo I d. C. tal y como establece Broneer por primera vez en 1930. Esta fecha ha sido aceptada generalmente, con algunas matizaciones (Loeschcke, Palol, Ponsich, Heres, Szentleleky y Leibundgut la adelantan hasta el 25 d. C.; Lamboglia restringe su fabricación al reinado de Vespasiano), pero todos los investigadores están de acuerdo en que es más tardía que Dressel 9-11.

Mayores problemas plantea su desaparición, a lo que contribuye el hecho de que pocas clasificaciones hayan deslindado este grupo de los tipos 15 y 16, de cronología algo más tardía. En principio parece que la fecha más apropiada se establece en torno al 100., aunque algunos autores lleven estas piezas hasta Adriano (Deneauve, Bailey), e incluso mediados del siglo II (Provoost, Leibundgut). 


\section{Tipo Dressel 15}

(Walters, 84; Broneer, XXIV; Palol, 9; Goldman, XIV; Dressel-Lamb., 15; Ponsich, II, B-2; Deneauve, VD; Szentleleky, b-8; Heres, D; Alarçao-Ponte, B-I, 2b; Bailey, IC)

La Dressel 15 parece una forma intermedia entre la Dressel 11 y la 14, ya que aún conserva las volutas dobles atrofiadas, pero por lo demás es exactamente igual. Los catálogos tipológicos las consideran conjuntamente. Puede confundirse con bastante facilidad con la Dressel 11 con asa, lo que no descartamos que haya ocurrido en alguna ocasión. Se le asigna la misma cronología que al tipo anterior. No todos los autores registran su existencia.

\section{Tipo Dressel 16}

(Walters, 83 y 85; Loeschcke, V; Broneer, XXIV; Ivanyi, VI; Palol, 9; Goldman, XIV; Dressel-Lamb. 16; Lerat, III-2, C; Ponsich, III-A, 1 y 2; Deneauve, VD; Szentleleky, b-8; Heres, D; Provoost, IV-3, 1a; Leibundgut, XIV-XV, Bailey, IC)

Muy parecida a la Dressel 14, pero el cuerpo globular ya anticipa las lucernas de disco. Para Dressel tiene decoración de ovas en el margo. A excepción de Ponsich, que la considera un grupo independiente, el resto de los autores la integra en el mismo grupo que los dos tipos precedentes, con idéntica datación. El susodicho autor hace hincapié en su caracter más tardío (entre mediados y finales del siglo I d. C.). Lamboglia llega a conclusiones semejantes.

\section{Tipo Loeschcke VI}

\section{(Lerat, III-2, D)}

Lucernas de reducidas dimensiones, menores de $5 \mathrm{cms}$. Forma derivada de la de volutas (Dressel 11 y 14), en la que éstas desaparecen, dejando como resto dos botones en relieve a los lados del "rostrum" redondeado. Presenta siempre asa. Tan sólo aparece recogida en las clasificaciones de Lerat y Loeschcke.

Este autor sitúa la producción a lo largo de la segunda mitad del siglo I d. C. Desconocemos los motivos por los que el grupo no ha sido identificado por otros autores. Quizá se trate de una producción local.

\section{Tipo Loeschcke II}

(Ivanyi, V; Palol, 10; Deneauve, IVD; Szentleleky, b-6; Alarçao-Ponte, B-II, 1; Provoost, IV-2, $\left.1^{\mathrm{a}}, 4^{\mathrm{a}}\right)$

No puede considerarse estrictamente como una lucerna de volutas, pero se halla emparentada con éstas. Presenta un pico triangular aplastado y poco pronunciado, sin volutas. Aunque aparece recogido en algunos estudios, dista mucho de estar perfectamente definido. Los problemas se centran sobre todo en la cronología. Loeschcke les da un origen postaugusteo y una vigencia hasta finales del siglo I d. C; Palol, Provoost y Szentleleky se muestran de acuerdo, pero este último autor asegura que en Italia ya aparecen durante el gobierno de Augusto. Una opinión contraria muestran Ivanyi y Deneauve. El primero fecha el tipo a principios del II; Deneauve entre el cambio de era y mediados del I d. C. 
Broneer (seguido por Goldman) hace corresponder su tipo XX con el Loeschcke II, lo que resulta a todas luces una atribución erronea. En realidad aquel tipo resulta una variante similar al Dressel 14-16, con una decoración peculiar.

\section{LUCERNAS DE DISCO}

\section{Tipo Dressel 17}

(Loeschcke, VIIIK; Broneer, XXV-1; IvanyiI, VII; Goldman, XVI; Dressel-Lamb., 17; Lerat, III-3, C-1; Deneauve, VIID; Heres, Ed; Alarçao-Ponte, B-II, 4; Provoost, IV-3, 4a , 2a ; Leibundgut, XX; Bailey, O; Amare, IV-3, C)

Con el este tipo comienzan las lucernas de disco con piquera redondeada y sin volutas. Presentan un cuerpo circular, con amplia orla y asa anular perforada o maziza. Se distinguen por la morfología del "rostrum" y su unión con el cuerpo. Constituyen un grupo muy difundido por todo el mundo romano, que presenta los mismos problemas tipo-cronológicos que otros materiales de los siglos II-III, y no ha sido medianamente aclarado hasta los trabajos de Deneauve y Heres. A partir de la publicación de Bisi Ingrassia su origen ha sido establecido hacia el tercer cuarto del siglo primero de nuestra era (Bisi Ingrassia, 1977, 88-95).

La forma Dressel 17 se caracteriza por tener el pico separado del cuerpo por una línea curva marcada. Resulta una de las mejor conocidas. A excepción de Walters, Palol, Szentleleky y Ponsich, el resto de los investigadores recoge esta variedad. La cronología ha fluctuado mucho de unos a otros. Loeschcke la data entre Claudio-Neron y finales del siglo I, coincidiendo con Deneauve. Otros autores han proporcionado fechas más concretas: Ivanyi entre Claudio y Vespasiano; Broneer la segunda mitad del siglo I d. C.; Lamboglia el siglo II; Provoost los siglos II y III; Leibundgut desde finales del reinado de Augusto hasta mediados del II en Suiza. En general los autores coinciden en situar su origen hacia mediados del siglo I, pero discrepan respecto al final de la producción.

Ponsich no encuentra esta forma entre los materiales africanos, pero documenta una serie de variedades regionales desconocidas al otro lado del Mediterráneo.

\section{Tipo Dressel 18}

(Walters, 96; Loeschcke, VIIIK; Ivanyi, VII; Dressel-Lamb., 18; Lerat, III-3, C-1; Ponsich, III-B, 1; Deneauve, VIIA; Szentleleky, b-11; Heres, Ea; Alarçao-Ponte, B-II, 4; Provoost, IV-3, $2^{\mathrm{a}}, 1^{\mathrm{a}}$; Leibundgut, XX; Bailey, O)

Muy parecida al tipo precedente. La separación entre el pico y el cuerpo se realiza mediante una línea curva, pero ésta no es continua ya que se corta con el disco. No todos los autores la consideran un grupo separado del anterior. Para algunos la cronología también resulta coincidente (Loeschcke, Ivanyi, Lamboglia, Bailey, Leibudgut). Otros han encontrado notables diferencias. El inicio de la producción suele colocarse hacia el $50 \mathrm{~d}$. C. De nuevo encontramos discrepancias respecto a su desaparición, pero parece imponerse una opinión generalizada que lo sitúa entre el 150 y el 200 d. C. (Heres, Denauve, Provoost, entre otros). 


\section{Tipo Dressel 19}

(Lloeschcke, VIIIR; Broneer, XXV-4; Ivanyi, VII; Palol, 11C; Goldman, XVI; DresselLamb., 19; Lerat, III-3, C-1; Ponsich, III-B, 1; Deneauve, VIIA; Szentleleky, b-11; Heres, Ea; Alarçao-Ponte, B-II, 5; Provoost, IV-3, 2a , 3ª; Bailey, O; Amare, IV-3, A)

Dos trazos más o menos rectos dispuestos enforma oblicua separan la piquera del disco. Este tipo parece una evolución de los dos anteriores, y las líneas de separación no llegan a ser totalmente rectas. La cronología resulta muy parecida a la Dressel 18. Deneauve la concreta entre el 50 y el $150 \mathrm{~d}$. C., en lo que le sigue la mayoría de los autores posteriores (Heres, Provoost, Leibundgut). Otros mantienen la misma que para Dressel 17 y 18 (Loeschcke, Broneer, Ivanyi, Palol).

\section{Tipo Dressel 20}

(Walters, 95; Broneer, XXV-3; IvanyiI, VII; Palol, 11A; Goldman, XVI; Dressel-Lamb., 20; Lerat, III-3, B; Ponsich, III-B, 1; Deneauve, VIIA; Szentleleky b-11; Heres, Eb; Alarçao-Ponte, B-II, 3; Provoost, IV-3, 3a , 1 a Leibundgut, XXI-XXII; Bailey, P; Amare, IV-3, Ba)

El "rostrum" está separado del cuerpo por una incisión horizontal y dos pequeños trazos oblicuos, con un punto en cada uno de los vértices. Resulta muy común entre todos los conjuntos estudiados, aunque Loeschcke no la documenta. Cronología idéntica a los dos tipos anteriores. Tan solo Leibundgut registra su continuidad hasta finales del II en Suiza.

\section{Tipo Loeschcke VIIIL}

(Broneer, XXV-2; Ivanyi VII; Goldman, XVI; Lerat, III-3, B; Ponsich, III-B, 1; Deneauve, VIIA; Szentleleky, b-11; Heres, Ec; Alarçao-Ponte, B-II, 3; Provoost IV-3, 3a $2^{\text {a }}$; Leibundgut, XX; Bailey, O; Amare, IV-3, Ba)

El "rostrum" se separa del disco por medio de una incisión horizontal o ligeramente curvada. DRESSEL no documenta esta forma, pero resulta bastante conocido en otras colecciones. La cronología propuesta resulta idéntica a la de los tres grupos precedentes.

\section{Tipo Dressel 21}

(Dressel-Lamb, 21; Provoost, IV-3, 3a , 3a)

La piquera redondeada se une directamente al disco por medio de dos líneas rectas, dejando un pequeño "canal" de comunicación entre ellos. Variante local, sólo recogida por Dressel y Provoost. Lamboglia la data durante el siglo II; Provoost opta por un cronología más amplia, desde mediados del I hasta el siglo III d. C. Morfologicamente parece relacionada con los tipos anteriores.

\section{Tipo Dressel 24}

(Broneer, XXVII; Ivanyi, X; Palol, 11C; Goldman, XVIII; Dressel-Lamb., 24; Lerat, III-3, C-2; Ponsich, III-B, 2; Deneauve, VIIB; Szentleleky, b-12; Heres, Ei; Alarçao-Ponte, B-II, 5; Provoost, IV-3, 2a $3^{a}$; Bailey, O) La forma Dressel 24 se caracteriza por tener la piquera separa- 
da del cuerpo por dos trazos oblicuos en forman un trapecio con el límite del disco. El margo es más ancho que en los ejemplares citados hasta el momento. Puede confundirse con la Dressel 19 , pero existen grandes diferencias entre ellas. Broneer fue el primero en hablar de un origen dentro del mundo griego, así como una cronología más tardía que otras lucernas de disco, en lo que no todos están de acuerdo. Según este autor el siglo II corresponde al momento de producción de las mismas a gran escala; Para Deneauve se concentraría entre el 150 y el 2OO; Otras clasificaciones la llevan hasta principios del III (Szentleleky) e incluso hasta el siglo IV (Heres. Varios investigadores no distinguen temporalmente entre este tipo y el resto de las lucernas de disco (Ponsich, Lamboglia).

\section{Tipo Dressel 25}

(Walters, 102; Broneer, XXVII; Ivanyi, X; Goldman, XVIII; Dressel-Lamb., 25; Lerat, III-3, C-2; Ponsich, III-B, 2; Szentleleky, b-12; Heres, Ei; Provoost, IV-3, 2a 3ª; Bailey, O)

Similar a la Dressel 24 pero con el margo más estrecho y dos protuberancias horizontales sobre el mismo, colocadas diametralmente. Todas las observaciones sobre la morfología y la datación del tipo anterior resultan válidas para éste.

\section{Tipo Dressel 27}

(Walters, 100; Loeschcke, VIIIH; Broneer, XXV-1; Ivanyi, VII; Palol, IIB; Goldman, XVI; Dressel-Lamb., 27; Lerat, III-3, C; Ponsich, III-C; Deneauve, VIIIA; Szentleleky, b-11; Heres Ee; Alarçao-Ponte, B-II, 6; Provoost, IV-3, 5a; Leibundgut, XX; Bailey, Q; Amare, IV-3, D)

Lucerna de disco bastante común. La separación entre el pico y el cuerpo se realiza por medio de dos trazos curvilíneos, que dan al "rostrum" una forma acorazonada. La cronología aún no está aclarada. Loeschcke ya opinaba que eran más tardías que otras de disco. Broneer estableció por primera vez sus márgenes temporales entre el 75 y el $100 \mathrm{~d}$. C. En general los trabajos más recientes consideran válida la fecha de inicio de la producción, pero prolongan su duración a lo largo del siglo II (Leibundgut), hasta principios del III (Heres), e incluso finales de este siglo (Bailey). Este último autor, juntamente con Alarçao, son los únicos que adelantan esta forma hasta principios del siglo I. No todos los catálogos distinguen entre las lucernas cordiformes y el resto de las de disco.

\section{Tipo Dressel 28}

(Walters, 101; Loeschcke, VIIIH; Broneer, XXV-1; Ivanyi, VII; Palol, IIB; Dreseel-Lamb., 28; Goldman, XVI; Lerat, III-3, D; Ponsich, III-C; Deneauve, VIIIB; Szentleleky, b-11; Heres, Ef; Alarçao-Ponte, B-II, 6; Provoost, IV-3, 5a; Leibundgut, XX-XXII; Bailey, Q; Amare, IV-3, D)

Aunque suelen aparecer formando parte del mismo grupo, se diferencian de las anteriores en que el margo aparece decorado con motivos diversos: guirnaldas, líneas de perlas, vides y pámpanos, etc. A partir del estudio de Deneauve se consideran más tardías. Este autor las sitúa entre el 150 y el 200, pero Heres, Leibundgut y Bailey retrasan hasta el siglo III su fabricación. Algunos trabajos, considerando que las lucernas con piquera acorazonada forman un único grupo, dan fechas muy dispares (Ponsich el siglo III, Broneer el último cuarto del siglo I d. C.). Se nos plantea la duda si estos autores no habrán constatado unicamente uno de los dos tipos, ampliando su cronología al otro. 


\section{TipoDressel 26}

(Walters, 99; Ivanyi, VII; Dressel-Lamb., 26; Deneauve, VIIID; Heres, Ef; Bailey, Q)

Lucerna de disco que conserva un esbozo de volutas entre el pico y el margo. Se halla suficientemente definida, pero no aparece frecuentemente. Deneauve la data en el siglo III, aunque Walters y Heres adelantan su aparición hasta el siglo II, perdurando durante el siguiente.

\section{LUCERNAS DE CANAL O "FIRMALAMPEN"}

Constituyen un grupo bastante homogéneo y bien individualizado, uno de los mejor conocidos del mundo romano. Sus características formales pueden resumirse en la simplicidad: cuerpo troncocónico, amplia orla inclinada hacia el exterior con dos pequeños abultamientos rectangulares en relieve sobre ésta, y una alta moldura abierta o cerrada respecto al pico. Esta peculiaridad ha permitido su agrupación en tipos diferentes. Disco plano, normalmente sin decoración o con algún motivo aislado. Suelen llevar en la base la marca del fabricante.

El lugar de producción original se ha establecido en el valle del Pó, desde donde se extienden a toda la parte occidental del Imperio. Los motivos de esta rápida difusión hay que buscarlos en simplificación formal, que permitía grandes facilidades de fabricación y transporte. En el ámbito griego son muy escasas (Broneer sólo identifica seis fragmentos).

En principio la investigación sólo identificó dos variantes, a las que más tarde se añade una tercera, y alguna otra problemática.

\section{Tipo Dressel 5}

(Walters, 90-92; Loeschcke, X; Ivanyi, XVI; Palol, 13; Dressel-Lamb., 5C Y 5D; Lerat, III-5, A; Ponsich, VA; Deneauve, IXA; Szentleleky, b-10; Alarçao-Ponte, B-IV, 1; Provoost, IV-5, 2a 1a; Leibundgut, XXVI y XXX; Bailey, N-3; Amare, IV-4, Aa)

Presentan una piquera larga, comunicada con el disco por un canal abierto. Este tipo aparecía ya en la clasificación de Dressel. Constituye un volumen de material notable en la mayoría de los yacimientos. Loeschcke llegó a la conclusión que las lucernas de canal abierto, que comprenden sus variedades X y XK podían datarse entre el 75 y el 100. La mayoría de los autores está de acuerdo en que las "Firmalampen" de canal abierto resultan una variedad tipológica más evolucionada que las variedades de canal cerrado, y su momento de apogeo se concentra en el siglo II (Palol, Lamboglia, Alarçao, Bailey). Leibundgut prolonga el uso de las abiertas hasta el siglo IV. Ponsich y Szentleleky no distinguen temporalmente entre abiertas y cerradas, y atribuyen a las lucernas de canal una cronología amplia, entre época Flavia y el siglo III.

\section{TipoDressel 6}

(Loeschcke, XK; Ivanyi, XVII; Palol, 13; Dressel- Lamb., 6; Ponschich, VB; Szentleleky, b10; Provoost, IV-5, 2a , 2a; Leibundgut, XXXII; Bailey, N-4; Amare, IV-4, Ab)

Todas las características formales y cronológicas del tipo Dressel 5 resultan aplicables a éste, que sólo se diferencia del anterior por las menores dimensiones del pico. También fue identificado por Dressel. 


\section{Tipo Loeschcke IX}

(Walters, 93-94; Broneer, XXVI; Ivanyi, XV; Palol, 13; Dressel-Lamb., 5A Y 5B; Lerat, III5, B; Ponsich, VC; Deneauve, IXA; Alarçao-Ponte, B-IV, 1; Provoost, IV-5, 1ª Leibundgut, XXIII; Bailey, N-1 y N-2; Amare, IV-4)

La variedad de lucernas con canal cerrado, aislado del disco y piquera alargada es mencionada por primera vez por Loeschcke, que le dió una fecha ligeramente anterior a las abiertas. Se ha precisado mucho mejor su cronología entre el inicio de la dinastía Flavia y el paso del siglo I al II (Palol, Lamboglia, Leibundgut), con perduración hasta Trajano (Ivanyi, Bailey).

La variedad con piquera corta sólo es mencionada por Provoost (IV-5, 1a) y Amare (IV-4).

\section{TipoWalter 68}

(Ivanyi, VI; Palol, 14; Lerat, III-4; Ponsich, II-B, 3; Deneauve, XII; Szentleleky, b-8 Y b-13; Provoost, IV-5, 3a)

Lucerna de canal curvo, con amplia orla decorada o lisa. Resultan problemáticas, ya que no todos los autores las consideran relacionadas con las "Firmalampen". Palol y Deneauve son de ésta opinión, mientras Ponsich y Lerat consideran este tipo como derivado de las lucernas de volutas de piquera redondeada.Szentleleky recoge la misma lucerna dentro de dos denominaciones diferentes. Quizá existen dos variedades muy parecidas, o tal vez se han cometido errores de clasificación. Consecuentemente no existe acuerdo alguno sobre la cronología, que fluctúa entre el siglo II y el IV.

\section{OTROS TIPOS DE LUCERNAS}

\section{Tipo Dressel 22}

(DresselL-Lamb., 22; Deneauve, II; Provoost, V-1, 1a; Leibundgut, XXVIII; Bailey, M)

Este tipo se considera una evolución de las "Vogelkopflampen" republicanas, por lo que se les da el mismo nombre. Presentan un cuerpo aplastado, asa transversal, piquera en yunque y forma de lira, sin separación entre disco y orla. Decoración muy característica, con incisiones en "V" en torno al orificio de alimentación, y esquemáticas cabezas de ave junto al pico. De ahí que reciban la misma nomenclatura que las lucernas de cabeza de pájaro originales, aunque la decoración constituya un elemento tipologicamente secundario. Parece que la esquematización del tipo obedece a las facilidades de embalaje, transporte y sujección a la pared.

Su cronología parece muy amplia, entre mediados del I d. C. y los siglos III-IV, pero aun no está bien definida. Bailey no la prolonga más alla de Adriano. Tampoco resultan suficientemente aclarados los pasos intermedios entre los dos grupos de "Vogelkopflampen".

\section{ALGUNAS PROPUESTAS FINALES}

A la vista de este complicado panorama nos atrevemos a realizar algunas propuestas destinadas a facilitar en el futuro el acercamiento de los investigadores al tema. Se hace necesario un nuevo enfoque en los estudios tipológicos sobre lucernas de cerámica, que elimine algunos de los errores cometidos hasta ahora. 
No es necesario extendernos sobre el hecho de que no existe una evolución lineal en la morfología de las lucernas. El concepto de un buen número de tipos de corta cronología que se sucedían rapidamente ha sido abandonado. En la actualidad cualquier clasificación válida debe combinar en mayor o menor porcentaje las características formales y la cronología derivada, con cierta jerarquización, pero no deja de ser un modelo explicativo. Nunca puede considerarse un hecho absoluto e inamovible.

Se debe evitar en la medida de lo posible la creación de nuevas tipologías-morfologías, que dificultan y entorpecen la investigación, y utilizar las denominaciones ya creadas. Estas resultan lo suficientemente abundantes, y ofrecen bastantes posibilidades cronológicas y tipológicas para adecuarse al interés concreto de cada autor. No podemos postular una supresión inmediata de las correspondencias formales de cada tipo en estudios posteriores, pero se hace imprescindible tender hacia una denominación unitaria, utilizando las dos o tres clasificaciones más completas y conocidas (tal vez Dressel, Loeschcke y Deneauve). Aún así, y manteniendo una nomenclatura perfectamente reconocible, en los estudios pormenorizados pueden y deben utilizarse los trabajos de otros investigadores que, elaborados con criterios diferentes, arrojan luz sobre problemas concretos.

Resulta patente la necesidad de publicar todos los materiales inéditos de los fondos de los museos, así como los que vayan saliendo a la luz en las diferentes excavaciones, con el fin de elaborar grandes catálogos regionales donde cotejar las piezas. Pero la comparación debe ser selectiva, teniendo en cuenta la naturaleza de las piezas.

Cada yacimiento posee sus propias características,tales como duración temporal, orbita de influencia, importancia político-administrativa, y conexión geográfica y económica con los centros de producción cerámicos. Cualquier estudio comparativo entre dos conjuntos de lucernas de distinta procedencia debe de tener en cuenta estas cuestiones. Establecer relaciones en un plano de igualdad entre piezas de dos yacimientos de distinta categoría o entre lucernas de un solo núcleo y de una región más amplia puede falsear las conclusiones y originar auténticas aberraciones arqueológicas. Los paralelos iconográficos siempre serán aspectos interesantes, pero deben considerarse conjuntamente con la cuantificación de los materiales y las características arqueológicas del asentamiento, aunque sepamos poco del mismo. En la medida de lo posible se deben comparar los conjuntos de lucernas pertenecientes a núcleos o regiones similares.

Combinando la información estratigráfica con otros aspectos como el análisis iconográfico y el seguimiento de las redes de comercialización hemos de determinar, si es posible, la zona de origen de cada tipo, y deslindar entre producciones generales y variedades locales. Hasta hace poco tiempo se habian considerado las marcas de taller como un criterio exacto para determinar el origen de las piezas firmadas. Cada vez resulta más evidente que las imitaciones y el comercio de moldes con sello han llevado a algunas deducciones erroneas. Excepto en el caso de materiales bien seriados y constatados arqueológicamente, la firma a lo sumo es un indicativo del origen de la forma pero no de la pieza concreta que estudiamos. Los análisis de pastas pueden desempeñar un papel determinante para clarificar este panorama. De la misma manera, la datación de este tipo de piezas no puede hacerse por si mismas, sino en relación con otros materiales asociados. La abundancia de un tipo concreto de piezas en una región no puede interpretarse inmediatamente como una producción local, tal y como se hizo en el caso de las lucernas de volutas itálicas. Actualmente está comprobado el origen minorasiatico de las mismas.

Hemos de advertir por último contra las identificaciones apriorísticas de algunos fragmentos aislados insuficientemente contrastados. Resulta preferible prescindir de los datos cronológicos 
que puedan aportar a forzar su clasificación de acuerdo con conclusiones preestablecidas. Sólo cuando los rasgos morfológicos y decorativos de una pieza corresponden exactamente a los de un grupo bien individualizado debe citarse como perteneciente al mismo. 


\section{BIBLIOGRAFIA}

AMARE TAFAlla, Ma . T. 1988: Lucernas romanas en Aragón, Zaragoza.

AlarÇAO, A. M. Y DE PONTE, S. 1976: "les lampes" en "Céramiques diverses et verres", Fouilles de Conimbriga, VI, Paris, 93-114, lams. XXIII-XXX.

AlvareZ-Oossorio, F. 1942: "Lucernas o lámparas antiguas de barro cocido del Museo Arqueológico Nacional", A. E. A. XV, 271-287.

BAILEY, D. M. 1975-80: A Catalogue of the Lamps in the British Museum, Londres.

I: Greek, Helenistic and Early Roman Pottery Lamps.

II: Roman Lamps made in Italy.

BALIL, A. 1982: "Revisión de la cronología de algunas lucernas romanas de Ampurias", IV Col-loqui Internacional d'Arqueologia de Puigcerdá: Estat actual de la recerca arqueologica a l'Istme Pirinenc. Homenatge al Dr. Oliva Prat, Puigcerdá, 1980, 247-249.

BISI INGRASSIA, A. M. 1977: "Le lucerne fittili dei nuovi scavi di Ercolano", L'Instrumentum Domesticum di Ercolano e Pompei nella prima etá imperiale, Quaderni di Cultura Materiale, 1, 73-104.

Broneer, O. 1930: "Terracotta Lamps", Corinth IV, II, Cambrigde.

DeBrun, P. y CAGniere S. 1937: Les Lampes antiques du Musée Calvet d'Avignon, Carpentras.

DenEAUVE J. 1969: Lampes de Carthage, Paris.

Doumergue, F. 1932: "Lampes antiques en terre cuite" en "Catalogue raisonné des objects archéologiques contenus dans le Musée Municipal d'Oran”, Bulletin de la Société de Géographie et 'Archéologie d'Oran 53, 362-380.

Dressel, H. 1899: "Lucernae Formae", C. I. L. (Inscriptiones Urbis Romae Latinae. Instrumentum Domesticum) XV, II, 1, lam. III.

Fernandez Chicarro C. 1952-3: "La colección de lucernas antiguas del Museo Arqueológico de Sevilla", Memorias Museos Arqueológicos provinciales XIII-XIV, 61-124.

FINK, J. 1901: "Formen und Stempel römischer Thonlampen", Sitzüngsberichte München 1900, 685-703.

Goldman, H. 1950: Excavations at Gözlü Kule, Tarsus. I. The Hellenistic and roman Period, Princeton, 84-134, lams. 93-113.

HAKEN, R. 1958: Roman Lamps in the Prague National Museum and in other Czechoslovak Collections, Acta Musei Nationalis Pragae, Serie A: Historia, XII, 1, Praga.

Heres, G. 1972: "Die römischen Bildlampen der Berliner Antiken-Sammlung" Schriften zur Geschichte und Kultur der Antike 3

IVANYI, D. 1935: "Die pannonischen Lampen. Eine typologisch-chronologische Übersicht", Dissertationes Pannonicae 2, 2.

Lamboglia, N. y Beltran, A. 1952: “Apuntes sobre cronología cerámica”, Caesaraugusta 3, 87-89, lams. X-XIII.

LEIBUNDGUT A. 1977: Die römischen lampen in der Schweż, Berna.

LERAT, L. 1954: "Les Lampes antiques" en "Catalogue des Collections Archéologiques de Besançon", Annales litteraires de l'Université de Besançon, 2, I, 1.

LOESCHCKE, S. 1919: Lampen aus Vindonissa, Ein Beitrag zur Geschichte von Vindonissa und des antiken Beleuchtungwesens, Zurich.

PALOL, P. de 1948-9: "La colección de lucernas romanas de cerámica procedentes de Ampurias en el Museo Arqueológico de Barcelona”, Memorias Museos Arqueológicos provinciales IX-X, 233-265.

PAvolinI, C. 1981: "Le lucerne nell'Italia romana” Società romana e produzione schiavistica, II, Merci, mercati e scambi nel Mediterraneo, Bari, 139-184. 
PONSICH, M. 1961: Les lampes romaines en terre cuitede la Maurètania Tingitane, Rabat.

Provoost, A. 1976: "Les lampes antiques en terre cuite. Introduction et essai de typologie générale avec des détaíls concernant les lampes trouvées en Italie”, L'Antiquité classique XLV, 5-39 y 550-586.

RICCI, M. 1974: "Per una cronologia delle lucerne tardo-repubblicane", R. S. L. XXXIX, 2-4, 168-234.

SZentleleky, Th. 1969: Ancient Lamps, Melanges d'Archéologie et d' Histoire I, Budapest.

Waldhauer, O. 1914: Die antiken Tonlampen. Kaiserliche Ermitage, San Petersburg.

WaLters, H. B. 1914: Catalogue of the Greek and Roman Lamps in the British Museum, Londres. 


\begin{tabular}{|c|c|c|c|c|c|c|c|c|}
\hline DRESSEL. & WALTERS & LOESCHCKE & BRONEER & IVANYI & PALOL & GOLDMAS & DRES-LAMB. & LERAT \\
\hline \multirow[t]{2}{*}{2} & $49-51$ & & & & 1 & 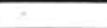 & 2 & $I I-C$ \\
\hline & I a. C. & & & & Augusto & & II-1 a.C. & \\
\hline \multirow[t]{2}{*}{3} & $73-74$ & & & & $2 \mathrm{~A}$ & & 3 & $I I I-1$ \\
\hline & $\mathrm{I} \approx \mathrm{C}$. & & & & Aug-Tib. & & $\begin{array}{l}\text { Tr-1 a.c. } \\
\text { Avguata. }\end{array}$ & \\
\hline \multirow[t]{2}{*}{4} & & & & & 3 & & 4 & $I I I-1$ \\
\hline & & & & & Augusto & & $\begin{array}{l}11-1 \text { a.c. } \\
\text { Ansuste }\end{array}$ & \\
\hline \multirow[t]{2}{*}{$9 \mathrm{~A}$} & $78-88$ & IA & $x x I I$ & I & $6 \mathrm{~A}$ & XII & $9 \mathrm{~A}$ & $111-2, A$ \\
\hline & Aug-Tib & Aug-Tib & I d.C. & $18-160$ & Aug-Tib. & I d.c. & Tiberio & \\
\hline \multirow[t]{2}{*}{$8 B$} & $78-88$ & IB & $x \times I I$ & I & 68 & $\mathrm{XII}$ & $9 \mathrm{~B}$ & $I I I-2, A$ \\
\hline & Aug-Tib & Tib-Claudid & I d.C. & $18-168$ & Tib-Claudio & I d.c. & Claudio & \\
\hline \multirow[t]{2}{*}{$9 \mathrm{C}$} & $78-80$ & IC & XXII & $\mathrm{I}$ & $6 \mathrm{C}$ & $\mathrm{XII}$ & $9 \mathrm{C}$ & III-2, A \\
\hline & Aug-Tib & $\begin{array}{l}\text { Jeron-pp10. } \\
\text { Elavios }\end{array}$ & I d.C. & $18-168$ & Seron-Vesp. & I d.C. & Vesp. & \\
\hline \multirow[t]{2}{*}{11} & 81 & IV & xxIII & II & 8 & XIII & 11 & $111-2,8-2$ \\
\hline & a-5a d. C & Augusto & $25-50$ & Tib-Vesp. & Clasd-Naron & $25-50$ & Tib-Claud. & \\
\hline \multirow[t]{2}{*}{12} & 88-89 & III & $x \times I-2$ & III & 7 & $\mathrm{XI}$ & 12 & $\mathrm{III}-2, \mathrm{~B}-1$ \\
\hline & e-5e d. C & Post. Aug. & Fin. I ace & Aug-Neron & Tib-Vesp. & TII. 1 ind & Tib-Claud. & \\
\hline \multirow[t]{2}{*}{13} & $86-87$ & III & $x X_{1}-2$ & III & 7 & $\mathrm{XI}$ & 13 & $\mathrm{III}-2, \mathrm{~B}-1$ \\
\hline & e-5ed.c. & Postaug. & Fin. I M.C? & Aug-Beron & Tib-Vesp. & 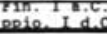 & Tib-Claud. & \\
\hline \multirow[t]{2}{*}{14} & 83,85 & $\nabla$ & XXIV & VI & 9 & $x I V$ & 14 & $\mathrm{III}-2, \mathrm{C}$ \\
\hline & B-5a d.C. & $25-180$ & $58-180$ & SO-ppio, II & 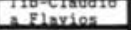 & $58-180$ & Vesp. & \\
\hline \multirow[t]{2}{*}{15} & 84 & & XXIV & & 9 & $\mathrm{XIV}$ & 15 & \\
\hline & $8-50$ d. C. & & $50-190$ & & $\begin{array}{l}\text { 110-Crinduro } \\
\text { Mlaylos }\end{array}$ & $58-160$ & Veap. & \\
\hline \multirow[t]{6}{*}{18} & 83.85 & y & $x x I v$ & VI & 9 & $X I V$ & 16 & $I I 1-2, C$ \\
\hline & a-5a d. C. & $25-100$ & $50-108$ & 58-ppio. II & $\begin{array}{l}\text { THo-chinuto } \\
\text { malavios }\end{array}$ & $58-180$ & Flavios & \\
\hline & & VIA & & & & & & III - 2, D \\
\hline & & $50-180$ & & & & & & \\
\hline & & II & & $\mathrm{v}$ & 18 & & & \\
\hline & & Post. Aug. & & Ppio. II & 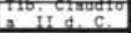 & & & \\
\hline \multirow[t]{2}{*}{17} & & VIIIX & $x x y-1$ & vit & & $x$ VI & 17 & III-3, C-1 \\
\hline & & $58-390$ & $58-180$ & Claud-Vesp. & & $50-10$ 잉 & II d.c. & \\
\hline \multirow[t]{2}{*}{18} & 98 & VIIIK & & VII & & & 18 & III-3, C-1 \\
\hline & II-III & $58-380$ & & Claud-Vesp. & & & II d.C. & \\
\hline 19 & & VIIIR & $x x y-4$ & VII & $11 \mathrm{C}$ & XVI & 19 & III-3, C-1 \\
\hline & & $5 e-300$ & $58-180$ & Claud-Vesp. & II d.c. & $58-100$ & II d.C. & \\
\hline 28 & 95 & & $x X Y-3$ & VII & $11 \mathrm{~A}$ & XVI & 20 & III $-3, B$ \\
\hline & $I I-I I I$ & & $58-180$ & Claud-Vesp. & II d.c. & $58-190$ & II d.C. & \\
\hline & & VIIIL & $x X y-2$ & VII & & XVI & & $111-3,8$ \\
\hline & & $58-3 e 8$ & $50-100$ & Claud-Vesp. & & $58-180$ & & \\
\hline 21 & & & & & & & 21 & \\
\hline & & & & & & & II d.c. & \\
\hline 24 & & & xxyII & $x$ & $11 \mathrm{C}$ & xvIII & 24 & $\mathrm{III}-3, \mathrm{C}-2$ \\
\hline & & & II d. C. & in, $I-f$ in. I & II d.c. & II d.c. & II d.c. & \\
\hline 25 & 182 & & XXVII & $x$ & & XVIII & 25 & $\mathrm{III}-3, \mathrm{C}-2$ \\
\hline & $11-111$ & & II d.C. & in. $I-f$ in. $I$ & & II d.c. & II d.c. & \\
\hline 27 & 100 & VIIIH & $x \times y-1$ & V1I & 118 & $x V I$ & 27 & $I I I-3, D$ \\
\hline & $I I-I I I$ & a partir 75 & $75-100$ & Claud-Vesp. & II d.C. & $50-100$ & II d.C. & \\
\hline 28 & 101 & VIIIH & $x x y-1$ & VII & 118 & XVI & 28 & $I I I-3, D$ \\
\hline & $I I-111$ & a partir 75 & $75-100$ & Claud-Vesp. & II d.c. & $58-189$ & II-III d.C. & \\
\hline 28 & 99 & & & vII & & & 26 & \\
\hline & II-IIt d.C. & & & Claudo-Vesp. & & & II d.c. & \\
\hline 5 & $90-92$ & $\mathrm{x}$ & & XVI & 13 & & SC, $5 \mathrm{D}$ & III $-5, A$ \\
\hline & Aug $-f$ in 1 & 75-111 d.c. & & Seron-Nerva & II d.C. & & II-III d.C. & \\
\hline 6 & & $\mathrm{xg}$ & & XVII & 13 & & 6 & \\
\hline & & $75-111$ & & in. $I-t$ in. $1 H$ & II d.C. & & II d.c. & \\
\hline & $93-94$ & $I X$ & $\mathrm{XXVI}$ & $X V$ & 13 & & $5 A, 5 B$ & III $-5, B$ \\
\hline & Aug $f$ in. I & a partir 75 & fin. $I-?$ & Vesp-Iraj. & $68-180$ & & $60-18 a$ & \\
\hline & 68 & & & VI & 14 & & & $111-4$ \\
\hline & I d. C. & & & 5e-ppio. 11 & II d.c. & & & \\
\hline 22 & & & & & & & 22 & \\
\hline & & & & & & & & \\
\hline
\end{tabular}




\begin{tabular}{|c|c|c|c|c|c|c|c|c|c|}
\hline & DESEAUVE & SZESTLEL. & HERES & RICCI & ALARCAO & PROYOOST & LEIBUNDG. & BAILEY & AMARE \\
\hline & $\mathrm{I}$ & $b-1$ & & DRES. $2,2 \mathrm{~A}$ & AI & III-1, 2a & & & $\mathrm{I}-2, \mathrm{Ba}$ \\
\hline & I a.c. & $25-75$ d.c. & & 100 a.C. -8 & & $275 \mathrm{a} . \mathrm{C} .-\mathrm{I}$ d. & . & & \\
\hline & III & & & DRES. $3,3 A$ & AII & $\mathrm{IV}-1,2 \mathrm{a}, 1 \mathrm{a}$ & 11 & & \\
\hline 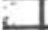 & I a.c. & & & $9 \mathrm{e}-\mathrm{g}=\mathrm{A} . \mathrm{C}$. & & in $I$ a $. C,-1$ d & $58-10$ a. C. & & \\
\hline & $\mathrm{II}$ & $b-2$ & & DRES. 4 & & $I V-1,2 a, 28$ & $\mathrm{I}$ & & $111-1$ \\
\hline 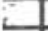 & I a.C. & Augusto & & $28=\mathrm{a}-18 \mathrm{~d} \cdot \mathrm{C}$ & & in $I=C .-1$ & 28 a.c. $-18 \mathrm{~d}$ & & \\
\hline 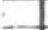 & IVA & $b-4$ & B & & B-1, $1 \mathrm{~A}$ & $\mathrm{IV}-2,1 \mathrm{a}, \mathrm{in}$ & $\mathrm{v}$ & IA & IV-2, As \\
\hline iv. & Aug-Claud. & Ppio. Tib. & Augusto & & & Aug-Tib. & d-25 d.C. & Aug-Flav. & \\
\hline 1 & IVA & $b-4$ & $B$ & & $\mathrm{~B}-1,1 \mathrm{~A}$ & $\mathrm{IV}-2,1 \mathrm{a}, 2 \mathrm{a}$ & vi & IA & IV $-2, \quad A b$ \\
\hline \multirow[t]{2}{*}{ v. } & Aug-Claud. & Tiberio & Auguste & & & Tib-Claud. & Tib-I d.c. & Augt-Flav, & \\
\hline & IVA & $b-4$ & $B$ & & $\mathrm{~B}-\mathrm{I}, 1 \mathrm{~A}$ & $1 \mathrm{v}-2,1 \mathrm{a}, 3 \mathrm{n}$ & vI1 & IA & $\mathrm{IV}-2, \mathrm{Ac}$ \\
\hline iv. & Flavios & $58-158$ & Augusto & & & Seron-II d.C & se-fin. I & Rug-Flav. & \\
\hline 1 & VA & $b-7$ & $\mathrm{c}$ & & $\mathrm{B}-\mathrm{I}, 2 \mathrm{~A}$ & $\mathrm{IV}-2,2 \mathrm{a}, 1 \mathrm{a}$ & XII & IB & IV-2, Bn \\
\hline v. & I d.C. & Tib-II d.C. & Aug-fin. I & & & -ppio il & Aug-5e d.C. & Aug-Traj. & \\
\hline 1 & VB & $b-3$ & Ac & & $\mathrm{B}-\mathrm{I}, 2 \mathrm{C}$ & & $x I$ & ID & IV-2, Bai \\
\hline v. & $38-50$ & 8-50 d.C. & Claud-Flav. & & $25-50$ d.c. & & Aug-5e d.C. & Aug-Traj. & \\
\hline 1 & VB & $b-3$ & $\mathrm{Aa}, \mathrm{Ab}$ & & $8-1,2 C$ & & $x$ & ID & IV -2 , Bai \\
\hline v. & $30-50$ & $0-50$ & Aug-Flav. & & $25-50$ d.C. & & Aug-5a d.C. & Aug-Traj. & \\
\hline 2 & vD & $b-8$ & D & & $B-1,2 B$ & $\mathrm{IV}-3,1 \mathrm{a}$ & $\mathrm{XIV}-\mathrm{XV}$ & IC & \\
\hline 1v. & $50-100$ & $25-108$ & $25-160$ & & & I d.C. -158 & $25-150$ d.c. & $58-120$ d.C. & \\
\hline 2 & VD & $b-8$ & D & & $B-1,2 B$ & & & IC & \\
\hline sv. & $58-100$ & $25-100$ & $25-160$ & & & & & 50-120 d.C. & \\
\hline 1,2 & VD & $b-8$ & D & & & IV $-3,13$ & $\mathrm{XIV}-\mathrm{XV}$ & IC & \\
\hline \multirow[t]{6}{*}{ 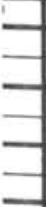 } & $58-180$ & $25-106$ & $25-100$ & & & I d.C. -158 & $25-150$ d.c. & $50-128$ d. C & \\
\hline & & & 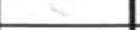 & & & & & & \\
\hline & IVD & $b-6$ & & & $\mathrm{~B}-\mathrm{II}, 1$ & IV $-2,1 \mathrm{a}, 4 \mathrm{a}$ & & & \\
\hline & $8-50$ & I d.c, & & & & Seron-11 d.c & & & \\
\hline & VIID & & Ed & & $\mathrm{B}-\mathrm{II}, 4$ & $I V-3,4 n, 20$ & $x x$ & 0 & $\mathrm{IV}-3, \mathrm{C}$ \\
\hline & 50-ppio. III & & I d.C. & & Claud-Seron & II-III d.C. & Aag-150 d.C. & Claud-15e & \\
\hline 1 & VIIA & $b-11$ & Es & & B-11. 4 & IV $-3,23,1 \mathrm{~s}$ & $\mathrm{xx}$ & 0 & \\
\hline III & $58-158$ & 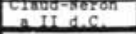 & 58-II d.C. & & Claud-Keron & 5e-11 d.C. & Aug -158 d.C. & Claud-15B & \\
\hline 1 & VIIA & $\mathrm{b}-11$ & Ea & & $8-11,5$ & $\mathrm{rv}-3,2 \mathrm{~s}, 3 \mathrm{a}$ & & 0 & IV $-3, A$ \\
\hline-111 & $50-158$ & 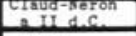 & So-II d.C. & & & $58-I I d . C$. & & Claud-150 & \\
\hline 1 & VIIA & $b-11$ & Eb & & B-II, 3 & $1 \mathrm{v}-3,3 \mathrm{a}, 1 \mathrm{a}$ & $x \mathrm{XXI}-\mathrm{XXII}$ & $\mathrm{P}$ & $\mathrm{IV}-3, \mathrm{Ba}$ \\
\hline III & $58-158$ & $\begin{array}{l}\text { Cradu } \\
\text { and d.C. }\end{array}$ & 58-II d.C. & & e partir Clau & . 50 -III d.C. & $\sin .1-f$ in. 11 & $f$ in Flav, -11 & \\
\hline 1 & VIIA & $b-11$ & $\mathrm{Ec}$ & & B-II, 3 & $1 \mathrm{v}-3,3 \mathrm{a}, 2 \mathrm{a}$ & $x x$ & 0 & $\mathrm{IV}-3, \mathrm{Bs}$ \\
\hline \multirow[t]{3}{*}{-111 } & $58-150$ & a II d.C. & $58-100$ d.c. & & a partir Clau & $50-111$ & Aug -150 d.C. & Claud-15e & \\
\hline & & & & & & $1 \mathrm{v}-3,3 \mathrm{a}, 3 \mathrm{a}$ & & & \\
\hline & & & & & & $50-$ III & & & \\
\hline 2 & VIIB & $b-12$ & Ei & & B-II, 5 & $1 \mathrm{~V}-3,2 \mathrm{a}, 3 \mathrm{a}$ & & 0 & \\
\hline III & $158-288$ & II-ppio. III & $I I-I V ~ d . C$. & & & 5e-II d.C. & & Clnud-15e & \\
\hline 2 & & $\mathrm{~b}-12$ & $\mathbb{E}_{i}$ & & & $\mathrm{IV}-3,2 \mathrm{a}, 3 \mathrm{a}$ & & 0 & \\
\hline \multirow[t]{2}{*}{-III } & & II-PDio. III & II $-I V$ d.C. & & & Se-II d.C. & & C1sud-158 & \\
\hline & VIIIA & b-11 & Ee & & B-11, $E$ & $\mathrm{IV}-3,5$ & $\mathbf{x x}$ & a & IV $-3, D$ \\
\hline \multirow[t]{6}{*}{ c. } & antes 160 & $\begin{array}{l}\text { Cinud-seron } \\
\text { MUdAC. }\end{array}$ & finI-ppio III & & antes IV & III-IV & Aug-15B d.C. & Pp10.I-258 & \\
\hline & VIIIB & $b-11$ & \begin{tabular}{|l|}
$\mathrm{E} f$ \\
\end{tabular} & & $B-11,6$ & IV $-3,5$ & $x x-x x I I$ & Q & IV-3, D \\
\hline & $158-288$ & ond.C. & $\mathrm{II}-\mathrm{III}$ d.C. & & antes IV & III-IV d.c. & fin.1-tin.tin & Pp10.I-250 & \\
\hline & VIIID & & Ef & & & & & a & \\
\hline & III d.C. & & II-III & & & & & Ppio.1-25日 & \\
\hline & IXA & $b-18$ & & & $\mathrm{~B}-\mathrm{IV}, 1$ & $\mathrm{IV}-5,2 \mathrm{a}, 1 \mathrm{a}$ & $x x \vee 1, x x x$ & $\mathrm{~N}-3$ & IV $-4, A s$ \\
\hline \multirow[t]{2}{*}{ III } & antes 100 & $78-250$ d.C. & & & II d.C. & II $-458 \mathrm{~d} . \mathrm{C}$ & fin. I-IV & $f$ in $F 1$ av -150 & \\
\hline & & $b=10$ & & & & $\mathrm{IV}-5,2 \mathrm{a}, 2 \mathrm{a}$ & $\mathrm{XXX11}$ & $N-4$ & IV $-4, A b$ \\
\hline \multirow[t]{2}{*}{ III } & & $70-258$ & & & & II $-450 \mathrm{~d} . \mathrm{C}$ & $180-$ IV d.C. & II d.C. & \\
\hline & IXA & & & & $\mathrm{B}-\mathrm{IV}, 1$ & IV $-5,1 \mathrm{a}$ & XxIII & $N-1, N-2$ & IV -4 \\
\hline 111 & antes 190 & & & & Trajano & 75-ppio. II & $78-100$ d.C. & 78-Traj. & \\
\hline \multirow[t]{4}{*}{3} & $x+1$ & $b-8, b-13$ & & & & IV-5, 3a & & & \\
\hline & IV d.C. & $75-100 / 111$ & & & & $\mathrm{II}-\mathrm{V} \circ \mathrm{VI} \mathrm{d} . \mathrm{C}$ & & & \\
\hline & II & & & & & $\mathrm{V}-1,1 \mathrm{a}$ & $x x$ xIII & $n$ & \\
\hline & & & & & & 58-225 d.C. & fin. $I-I V$ & Flav-Adriano & \\
\hline
\end{tabular}

